\title{
Simultaneous Endovascular Approach for Aortic Arch Aneurysm Associated with Aortic Valve Stenosis. What Have We Learned?
}

\author{
Joël Lapeze1, Guy Durand de Gevigney ${ }^{2}$, Didier Revel ${ }^{3}$, Olivier Jegaden ${ }^{4}$ \\ ${ }^{1}$ Department of Cardiovascular Surgery, Louis Pradel Hospital, Lyon, France \\ ${ }^{2}$ Department of Cardiology, Louis Pradel Hospital, Lyon, France \\ ${ }^{3}$ Department of Radiology, Louis Pradel Hospital, Lyon, France \\ ${ }^{4}$ Department of Cardiovascular Surgery, Cleveland Clinic Abu Dhabi, Abu Dhabi, UAE \\ Email: ${ }^{*}$ jegadeo@clevelandclinicabudhabi.ae
}

Received 22 January 2015; accepted 6 February 2015; published 11 February 2015

Copyright (C) 2015 by authors and Scientific Research Publishing Inc.

This work is licensed under the Creative Commons Attribution International License (CC BY). http://creativecommons.org/licenses/by/4.0/

c) (i) Open Access

\begin{abstract}
Aortic arch aneurysms are rarely isolated entities, and most frequently associated with either ascending or descending aorta pathologies. Association with aortic valve stenosis is uncommon and traditional surgical treatment is always challenging. Here we report a minimally invasive and endovascular management of these two pathologies in a 89-year-old man with LAD-stented ischemic cardiomyopathy. We describe our initial therapeutic strategy, per procedure difficulties and final management of this challenging case. Finally, we discuss the different therapeutic options for the endovascular treatment of aortic arch aneurysm associated with aortic valve stenosis.
\end{abstract}

\section{Keywords}

Aortic Arch, Endovascular Procedure, Aortic Stenosis, Transcatheter Aortic Valve Implantation

\section{Introduction}

In high risk patients, endovascular approach is currently being recommended for the treatment of aortic valve stenosis and thoracic aortic aneurysm with transcatheter aortic valve implantation (TAVI) and thoracic endovascular aortic repair (TEVAR) techniques, respectively [1]. We report one case of an aortic valve stenosis

\footnotetext{
${ }^{*}$ Corresponding author.

How to cite this paper: Lapeze, J., de Gevigney, G.D., Revel, D. and Jegaden, O. (2015) Simultaneous Endovascular Approach for Aortic Arch Aneurysm Associated with Aortic Valve Stenosis. What Have We Learned? International Journal of Clinical Medicine, 6, 81-84. http://dx.doi.org/10.4236/ijcm.2015.62012
} 
associated with an aortic arch aneurysm and both lesions were simultaneously treated. The different technical options are discussed.

\section{Case Report}

An 89-year-old man with a LAD-stented ischemic cardiomyopathy was diagnosed with a $70 \mathrm{~mm}$ sacciform aortic arch aneurysm on an angioscanner in the assessment of dizziness (Figure 1). Transthoracic echocardiography revealed a severe aortic valve stenosis (effective orifice area, $0.50 \mathrm{~cm}^{2} / \mathrm{m}^{2}$ ), moderate pulmonary hypertension (systolic pulmonary arterial pressure, $48 \mathrm{mmHg}$ ) and moderate impairment of the left ventricular ejection fraction (55\%). Clinically, the patient was in NYHA class 3, without arterial hypertension or neurological disorder. Biologically, plasmatic ionogram was normal except a creatinine clearance at $72 \mathrm{~mL} / \mathrm{min} / \mathrm{m}^{2}$. Logistic Euroscore I was $26 \%$ and STS score was $3.8 \%$. Considering the age of the patient, a minimally invasive double-staged approach was decided, with a 3-week interval between the two procedures.

The first step consisted in a debranching of the supra-aortic vessels through a mini-sternotomy approach without CPB and with a side-biting clamp, using a woven double velours bifurcated graft 18/9 mm (Platinum Hemashield, Boston scientific Corp., Natick, MA); the left subclavian artery was just tied. Postoperatice outcome was fine; there was no neurological or cardiac event and the patient was discharged from the hospital at Day 5 PO.

The second step should have consisted in a transfemoral TAVI followed by a TEVAR for the aortic arch aneurysm. Unfortunately, we managed to do the aortic valvuloplasty but we encountered great difficulties in passing a $29 \mathrm{~mm}$ Edwards Sapien $\mathrm{XT}^{\mathrm{TM}}$ (Edwards Lifesciences, Irvine, CA) through the aortic native valve: The Edwards RetroFlex ${ }^{\circledR}$ catheter had no support in the aortic arch, winding in the aortic aneurysm, with finally the impossibility to cross the valve and to implant the prosthesis in intra-annulus position. Thus, we decided to release the transcatheter aortic valve in the descending aorta, in order to treat the aneurysm first and to attempt again a TAVI procedure.

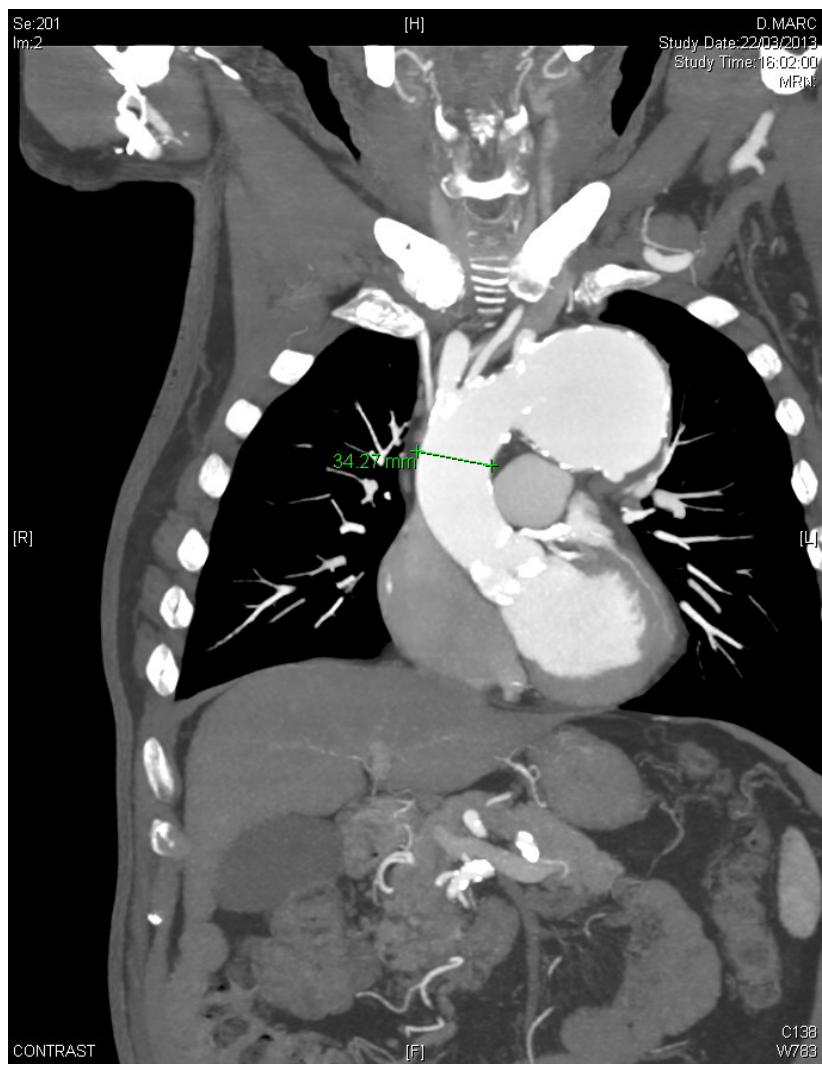

Figure 1. Preoperative enhanced CT scan showing the aortic arch aneurysm. 
The aortic arch and isthmus were covered by a $38 \times 167$ mm Valiant ${ }^{\mathrm{TM}}$ Thoracic Stent Graft (Medtronic Limited, Watford, Hertfordshire) which was passed through the first Sapien prosthesis. Then, we managed to implant another $29 \mathrm{~mm}$ Edwards Sapien XT aortic valve in intra-annulus position. We did not encounter any difficulty in crossing the aortic endograft with the transcatheter aortic valve and the graft provided a good support to cross the aortic native valve. The postoperative angiography demonstrated a good anatomic result of both procedures (Figure 2).

The postoperative outcome was free of any neurological or cardiac event. The pre-discharge echo showed a mean gradient of the aortic bioprothesis at $5 \mathrm{mmHg}$, without aortic regurgitation or paravalvular leak. The patient was discharged at home on Day 7 PO. At 8-month follow-up the patient is going well; the echo data were unchanged and an unenhanced CT scan demonstrated a stable aortic arch lesion well covered by the endograft.

\section{Discussion}

The association of TAVI and TEVAR procedures is always challenging and the different options have to be discussed by the heart team.

In this reported case, a transaortic TAVI procedure was one option, followed by the debranching of the supraaortic vessels through the same aortic site, with in a second step, a transfemoral TEVAR procedure to cover the aortic arch aneurysm. However, we found this sequence too tricky regarding the aortic entry point which would be localised either at the usual place of the introduction of the delivery catheter for TAVI but too distal for the debranching stage, or in the middle of ascending aorta, well adapted for debranching but too close to the aortic valve in the deployment of the Sapien prosthesis. The possibility to use two aortic sites was not considered according to the predictable frailty of the ascending aorta.

Our choice was an isolated debranching of the supra-aortic vessels first and then a transfemoral TAVI procedure followed by a TEVAR on the way. The rational thinking to use this chronology was to avoid the aortic valve prosthesis to get stuck into the endograft considering the aortic arch's curve. This strategy was proved false and a TEVAR procedure first was necessary to provide a good support to perform the crossing of the native aortic valve by the Edwards Retroflex delivery system.

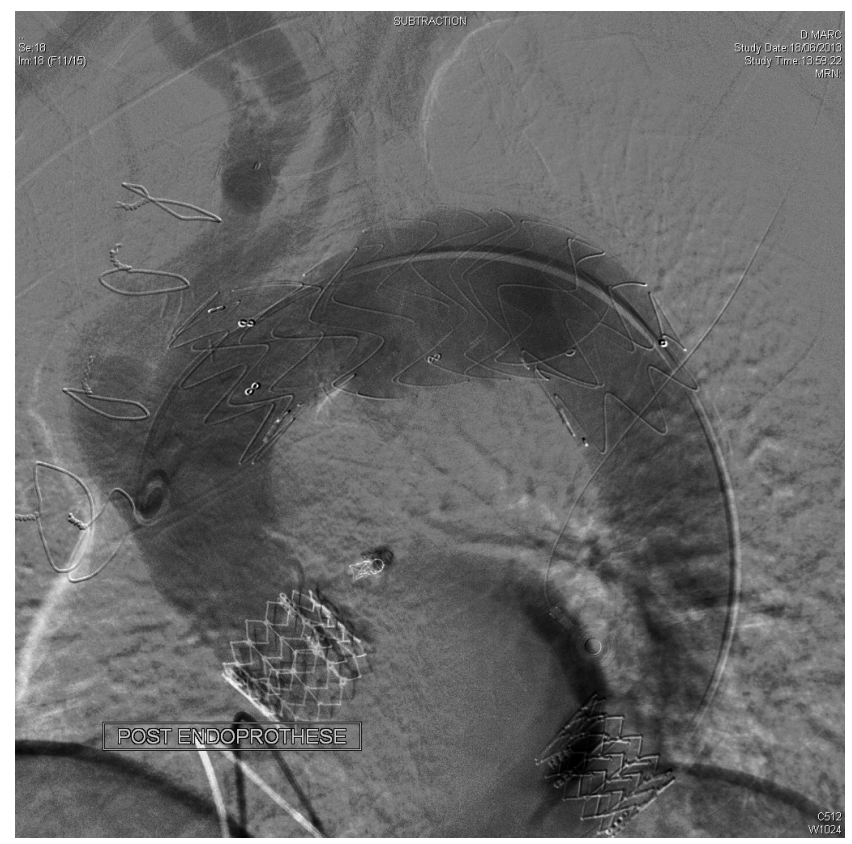

Figure 2. Angiography at the end of the procedure. The proximal Sapien prosthesis is in anatomical position without residual aortic regurgitation or paravalvular leak. The aortic arch aneurysm is well covered by the endograft without endoleak. The debranching and supra-aortic vessels are well perfused. The distal Sapien prosthesis is anchored in the distal descending aorta. 
Another option could had been to perform independently a transapical TAVI and a TEVAR. This strategy needs multiple surgical approaches but it had made the procedures easier. It would have been our last option if the second transfemoral TAVI procedure was not successful.

In our knowledge, no case of combined TAVI and aortic arch aneurysm endovascular treatment has been previously reported. As well as it has been described in TAVI procedures associated with TEVAR for thoracic descending or abdominal aortic aneurysm [2]-[4], and considering our experience, the femoral approach remains optimal and we advise to perform the aortic arch aneurysm exclusion first in order to facilitate the ascent of the TAVI delivery catheter. The low rates of stroke, vascular complications, paravalvular regurgitation and mortality associated with transfemoral delivery of the SAPIEN 3 (Edwards Lifesciences Inc., Irvine, California) aortic valve prosthesis confirm the accuracy of such a strategy; more, the new low-profile delivery system of the Sapien 3, could make easier the positioning of the aortic valve in such difficult anatomic situation [5]. However, simultaneous transaortic TAVI and debranching before TEVAR may be an alternative if the length of the ascending aorta is favourable.

\section{Conclusion}

The association of TAVI and TEVAR procedures is always challenging. Regardless the localisation of the aortic aneurysm, the femoral approach for simultaneous procedures is optimal and the sequential strategy with TEVAR first, must pave the way to the aortic valve for a safe TAVI procedure at the end. In case of aortic arch aneurysm, a transaortic TAVI associated with the debranching of supra-aortic vessels and then followed by a TEVAR procedure, may be an alternative strategy.

\section{References}

[1] Leon, M.B., Piazza, N., Nikolsky, E., Blackstone, E.H., Cutlip, D.E., Kappetein, A.P., et al. (2011) Standardized Endpoint Definitions for Transcatheter Aortic Valve Implantation Clinical Trials. JACC, 57, 253-269. http://dx.doi.org/10.1016/i.jacc.2010.12.005

[2] Drury-Smith, M., Garnham, A. and Khogali, S. (2012) Critical Aortic Stenosis in a Patient with a Large Saccular Abdominal Aortic Aneurysm: Simultaneous Transcatheter Aortic Valve Implantation and Drive-By Endovascular Aortic Aneurysm Repair. Catheterization and Cardiovascular Interventions, 80, 1014-1018. http://dx.doi.org/10.1002/ccd.23452

[3] Ghosh-Dastidar, M., Dworakowski, R., Lioupis, C., Maccarthy, P., Valenti, D., El Gamel, A., et al. (2011) The Combined Treatment of Aortic Stenosis and Abdominal Aortic Aneurysm Using Transcatheter Techniques: A Case Report. Journal of Cardiovascular Surgery, 52, 895-898.

[4] Chakraborty, B.R., Greason, K.L., Oderich, G.S., Bresnahan, J.F., Reeder, G.S., Suri, R.M., et al. (2013) Endovascular Abdominal Aortic Aneurysm Repair to Facilitate Access for Transcatheter Aortic Valve Implantation. Annals of Thoracic Surgery, 95, 1439-1441. http://dx.doi.org/10.1016/j.athoracsur.2012.08.083

[5] Webb, J., Gerosa, G., Lefevre, T., Leipsic, J., Spence, M., Thomas, M., et al. (2014) Multicenter Evaluation of a NextGeneration Balloon-Expandable Transcatheter Aortic Valve. JACC, 64, 2235-2243. http://dx.doi.org/10.1016/j.jacc.2014.09.026 
Scientific Research Publishing (SCIRP) is one of the largest Open Access journal publishers. It is currently publishing more than 200 open access, online, peer-reviewed journals covering a wide range of academic disciplines. SCIRP serves the worldwide academic communities and contributes to the progress and application of science with its publication.

Other selected journals from SCIRP are listed as below. Submit your manuscript to us via either submit@scirp.org or Online Submission Portal.
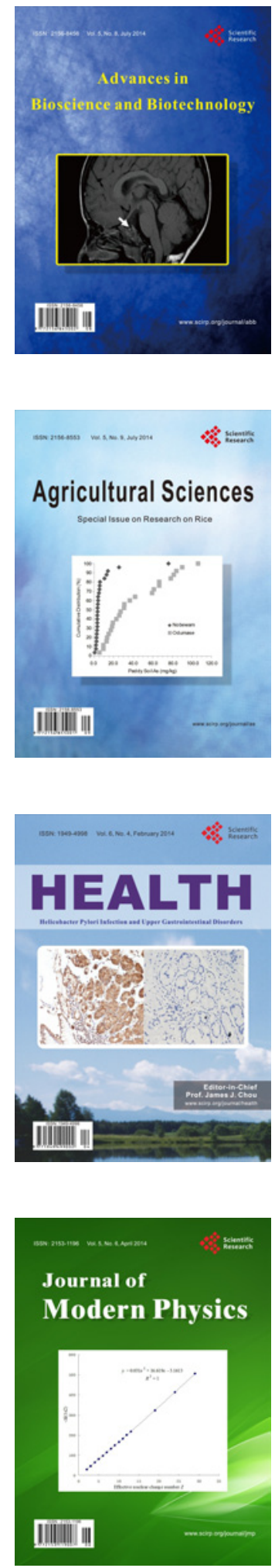
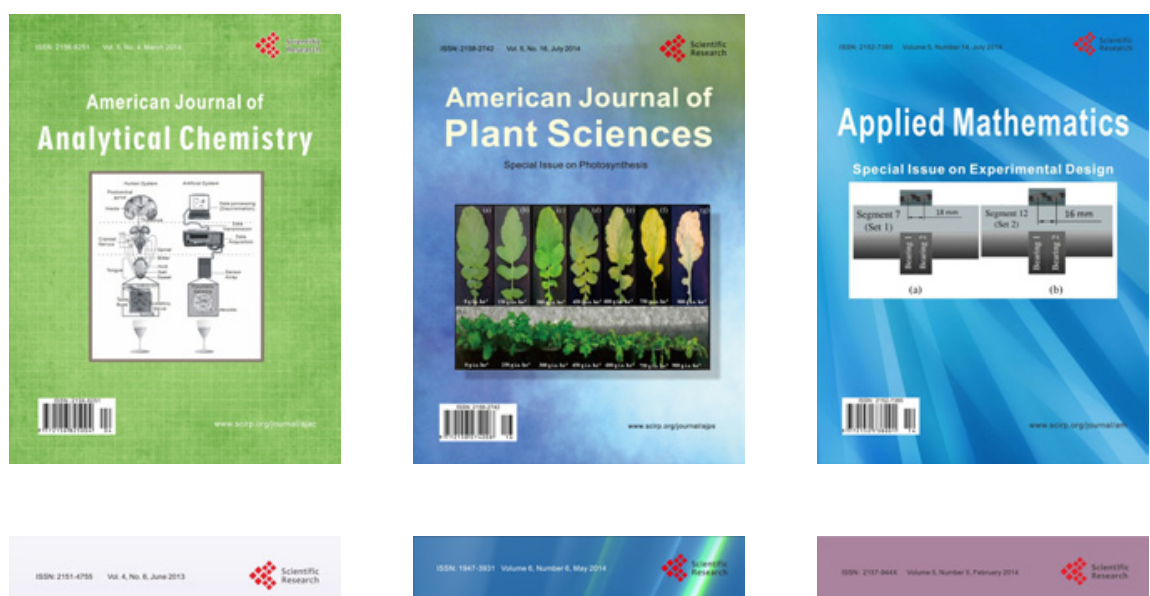

Creative Education
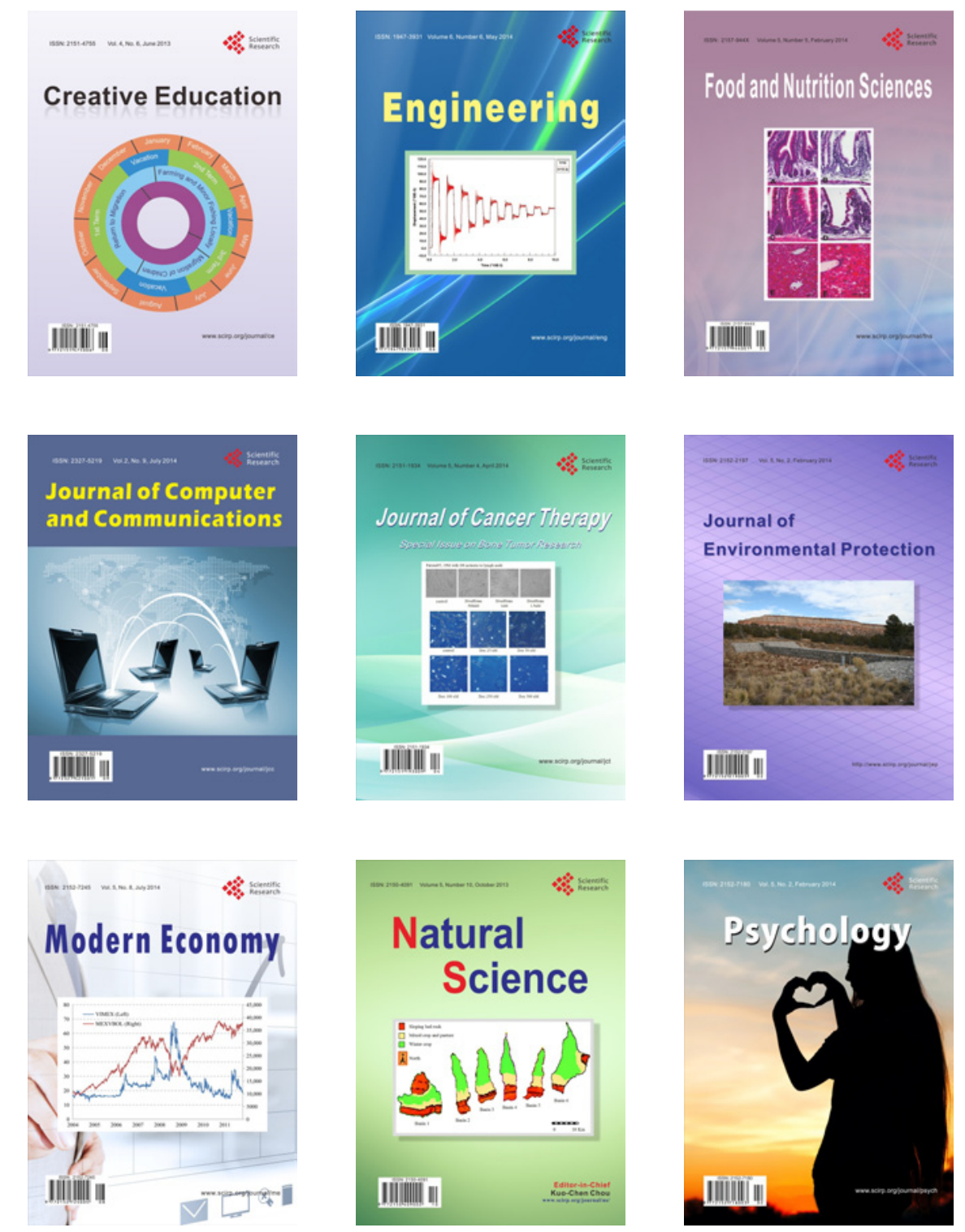